\title{
"O QUE TENHO A COMEMORAR?": A saúde mental de professores da educação básica de Garanhuns/PE
}

\author{
DEISE JULIANA FRANCISCO \\ Psicóloga - UFRGS; Doutora em Informática na Educação - PGIE/UFRGS. ORCID: http:// \\ orcid.org/0000-0003-2130-2588. E-mail: deisej@gmail.com \\ MYLENA CARLA ALMEIDA TENÓRIO RAMOS \\ Pedagoga- UFRPE/ UAG; Mestra em Educação- PPGE/ UFAL. ORCID: https://orcid.org/0000- \\ 0001-8036-1129. E-mail: mylena_dayvid@hotmail.com
}




\section{RESUMO}

O presente trabalho apresenta uma pesquisa realizada na rede municipal de ensino de Garanhuns/Pe. Tal pesquisa foi realizada para conclusão do curso de mestrado acadêmico do Programa de Pós-Graduação em Educação da Universidade Federal de Alagoas - UFAL. Este trabalho objetivou compreender a saúde mental do professor que atua nos anos iniciais do Ensino Fundamental, tendo como objetivos específicos mapear a rede municipal de ensino de Garanhuns com relação à quantidade de alunos com deficiência incluídos, bem como o perfil de um grupo de professores da rede. Para tanto, partimos do trinômio saúde-trabalho-educação, através do crescente aumento de estudos relacionados a essa temática, seguindo também o pressuposto de Clot (2010), no qual a clínica da atividade passa a ser utilizada em uma busca pela análise do trabalho e seu desenvolvimento, a fim de reacender o poder de agir dos trabalhadores, seja individual ou coletivamente. A pesquisa foi mista, com abordagem quali-quanti, sendo a produção de dados realizada através de questionários com questões quantitativas e qualitativas para mapeamento de aspectos relacionados à saúde dos participantes, realizada em três escolas da rede municipal que contam com o maior número de alunos incluídos, tendo como participantes 21 professores. A partir da análise pela estatística descritiva e partindo das categorias criadas, verificamos que os agravantes da saúde desses professores é algo presente, independente do processo de inclusão, sendo que o próprio ambiente causa angústia e sofrimento. Os resultados apontaram para uma insatisfação dos professores, tendo em vista a falta de formação, de estrutura física e suporte dos órgãos competentes, além da má remuneração e condições de trabalho.

Palavras Chave: Saúde Mental. Atividade Docente. Inclusão Escolar..

\section{“QUÉ TENGO A COMEMORAR?”: LA SALUD MENTAL DE PROFESORES DE LA EDUCACIÓN BÁSICA DE GARANHUNS/ PE}

El presente trabajo presenta una investigación realizada en la red municipal de enseñanza de Garanhuns/ Pe. Esta investigación objetivó comprender la salud mental del profesor que actúa en los años iniciales de la Enseñanza Fundamental, teniendo como objetivos específicos mapear la red municipal de enseñanza de Garanhuns con relación a la inclusión de los alumnos con discapacidad, así como el perfil de un grupo de profesores de la red. Para ello, partimos del trinomio salud-trabajo-educación, a través del creciente aumento de estudios relacionados a esa temática, siguiendo también el presupuesto de Clot (2010), en el cual la clínica de la actividad pasa a ser utilizada en una búsqueda por el análisis del trabajo y su desarrollo, a fin de reactivar el poder de actuar de los trabajadores, sea individual o colectivamente. La investigación fue mixta, con abordaje cuali-quanti, siendo la producción de datos realizada a través de cuestionarios con cuestiones cuantitativas y cualitativas para mapeamiento de aspectos relacionados a la salud de los participantes, realizada en tres escuelas de la red municipal que cuentan con el mayor número de alumnos incluidos, teniendo como participantes 21 profesores. A partir del análisis por la estadística descriptiva y partiendo de las categorías creadas, verificamos que los agravantes de la salud de estos profesores es algo presente, independiente del proceso de inclusión, siendo que el propio ambiente causa angustia y sufrimiento. Los resultados apuntaron a una insatisfacción de los profesores, teniendo en vista la falta de formación, de estructura física y soporte de los órganos competentes, además de la mala remuneración y condiciones de trabajo.

Palabras clave: Salud Mental. Actividad Docente. Inclusión Escolar.

P/Ullais Salvador, v. 3, n.3, p. 58-78, set./dez. 2018

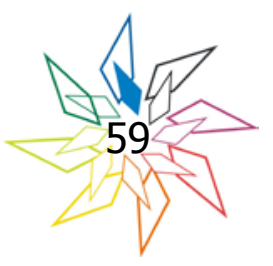


“WHAT DO I HAVE TO CELEBRATE?”: THE MENTAL HEALTH OF TEACHER OF BASIC EDUCATION OF GARANHUNS/PE

Este es un trabajo de investigación desarrollado como etapa inicial de un proyecto más amplio que culminará en la Disertación de Maestría Profesional en Educación sobre la manifestación de las habilidades especiales en Matemáticas en la Educación Básica en em Campo Grande, Mato Grosso do Sul, Brasil. Se trata de una mirada sobre las Altas Habilidades y Superdotación, a partir de la narrativa de un estudiante altamente habilidoso buscando analizar el Atendimiento Educacional Especializado por medio de investigación cualitativa con la contribución de la perspectiva del análisis de contenido propuesto por Bardin. Discurre sobre las características predominantes de los habilidosos matemáticamente, la importancia de las Narrativas para la formación del profesor y para comprender el lugar de donde habla el estudiante. Articula la narrativa con la revisión bibliográfica pautándose por el parámetro fenomenológico y se concluye por la importancia del acto de oír y dar voz al sujeto que está inserto en la realidad de aquel contexto.

Keywords: Mental Health. Teaching Activity. School Inclusion.

\section{“O QUE TENHO A COMEMORAR?": A SAÚDE MENTAL DE PROFESSORES DA EDUCAÇÃO BÁSICA DE GARANHUNS/PE}

\section{Introdução}

A presente pesquisa foi realizada para conclusão do curso de mestrado acadêmico do Programa de Pós-Graduação em Educação- PPGE da Universidade Federal de Alagoas - UFAL, na linha de pesquisa Educação e Inclusão de Pessoas com deficiência ou sofrimento psíquico, este trabalho foi escrito sob minha orientação pela mestranda coautora do mesmo.

No que diz respeito à escolha pela temática abordada neste trabalho, deu-se a partir do contato com a temática em uma disciplina cursada no Mestrado Saúde Mental e Educação ${ }^{1}$, a qual abordou a saúde mental nas esferas educacionais, deixando a possibilidade de inúmeras abordagens em meio a esse campo de atuação. Tendo em vista que nossa experiência acadêmica e profissional está ligada com a prática e o desenvolvimento de estratégias para os alunos com deficiência, o contato com a Psicologia do Trabalho e a saúde mental foi o pontapé inicial para o

${ }^{1}$ Disciplina ministrada pela professora Dra. Deise Julia Francisco, Programa de Pós-Graduação em Educação. 
desenvolvimento de um trabalho com a saúde mental dos professores que estavam atuando nesse processo de inclusão. Foi uma união dos âmbitos- saúde e educação -, a fim de abordar a dinâmica do professor como agente construtor e reprodutor do processo de inclusão nas escolas.

Nesse sentido, resolvemos optar pelo trabalho com a saúde mental e sua relação com o trabalho docente, pensando nos profissionais que lidavam com a inclusão escolar. Assim, tomamos com base a intensificação do trabalho do professor, no qual percebemos que há um crescimento de suas tarefas diárias e sobrecarga de atividades de trabalho. Como afirma Nóvoa (1997), há certa crença que uma das fontes geradoras de stress e mal-estar docente pode vir de um sentimento do professor quanto à ausência de domínio das novas e inesperadas situações pedagógicas do atual contexto profissional. E esse fator pode estar relacionado também à necessidade de recrutamento de professores, muitas vezes sem uma formação inicial básica, buscando atender o aumento da demanda de alunos, ou até mesmo, à necessidade de rever e mudar a prática e métodos que utilizam em suas atividades cotidianas, a fim de atender a um público diverso que chega às escolas.

Em educação, o trabalho docente e suas relações com a saúde vêm servindo de objeto de estudo de diversas áreas do conhecimento, sendo essa temática, alvo de atenção crescente nos últimos anos (TITTONE, 1994; ESTEVE, 1999; CODO, 1999; ANTUNES, 2002; CARLOTTO, 2002; GASPARINI, BARRETO e ASSUNÇÃO, 2005; MENDES, 2006; LEVY e SOBRINHO, 2010; BENDASSOLLI, 2011; SOUZA e LEITE, 2011; ARAÚJO e SOUSA, 2013; MACEDO e LIMA, 2017).

No que diz respeito à saúde mental do professor, percebemos que, com a constante modificação na atuação e no papel desse profissional, bem como as condições de trabalho, são criadas inúmeras situações que afetam suas capacidades físicas, cognitivas e afetivas. Para alcançar os objetivos propostos para a produção escolar e desenvolvimento de suas atividades, os professores acabam gerando "sobreesforços ou hipersolicitação de suas funções psicofisiológicas" (GASPARINI, BARRETO, ASSUNÇÃO, 2005, p. 192), o que desencadeia sintomas clínicos que apontam para os índices de afastamento do trabalho por transtornos mentais.

Quanto ao processo de trabalho docente, a escola é o campo de ação dos professores no qual estão as reais condições de trabalho. Ali é possível verificar os fatores propulsores de possíveis adoecimentos físico e mental desses atores que estão diretamente ligados ao processo de ensino e aprendizagem dos seus alunos. Isso é, ao mesmo tempo, um fator de desafio e uma necessidade para se entender as relações entre saúde-doença do trabalhador docente em meio ao crescente avanço da sociedade, às tecnologias, ao sistema capitalista e à inclusão da diversidade. 
Nesse sentido, a clínica da atividade citada por Clot (2007) traz para esse trabalho suporte ao campo de ação profissional, sendo esse um local no qual são realizadas análises a partir das reflexões dos sujeitos acerca de suas próprias ações. As contribuições desse referencial fornecem instrumentos teóricos e técnicos que possibilitam a compreensão das situações de trabalho, a fim de possibilitar que o sujeito possa desenvolver o poder de agir sobre o mundo e sobre si mesmo, de maneira individual e coletiva. A clínica da atividade é constituída pela busca de recursos teóricos e práticos, capazes de reabastecer o poder de agir de um coletivo profissional no seu meio de trabalho e de vida (CLOT, 2010).

Partindo dessa perspectiva, a presente pesquisa buscou analisar a saúde mental do professor que atua com inclusão de alunos com deficiência nas escolas regulares da rede municipal de ensino da cidade de Garanhuns-PE. Logo, a pergunta da pesquisa é: Como tem se manifestado a saúde mental dos professores da rede municipal de Garanhuns que atuam na educação inclusiva, desde sua perspectiva?

O objetivo geral foi construído como sendo: analisar como o professor do Ensino Fundamental - Anos iniciais -, de turmas regulares com alunos com deficiência, da rede pública municipal de Garanhuns/Pernambuco têm vivenciado a inclusão em termos de sua saúde mental. Os objetivos específicos são: mapear a rede municipal de ensino de Garanhuns com relação ao quantitativo de alunos com deficiência incluídos, bem como o perfil de um grupo de professores da rede; destacar as situações e os fatores que contribuem para o surgimento de sofrimento no exercício da profissão docente no processo de inclusão escolar, na perspectiva do professor.

Iniciamos as atividades através de uma seleção da amostra, realizada pela Secretaria Municipal de Educação, que nos disponibilizou três escolas para produção de dados. A primeira parte da pesquisa contou com um questionário, tendo em vista a abordagem quali-quanti, aplicado a 21 professores, a fim de construir um mapeamento dos participantes da pesquisa, em se tratando de perfil profissional, processo de saúde mental, adoecimento, angústias e desenvolvimento de suas atividades frente ao ambiente de trabalho.

\section{Embasamento teórico}

O trabalho é um processo que está presente na sociedade desde a sua base, é nele que se estabelecem as formas de relação entre os sujeitos e as classes sociais que a compõem, bem como cria relações de poder e conveniência, definindo o ritmo do cotidiano. O trabalho é algo que faz 
parte da história da humanidade, bem como de suas relações pessoais e sociais. É uma atividade que se constitui enquanto um dos propulsores para a evolução e modificação da sociedade, espaço onde as pessoas buscam sua identidade. Para Clot (2007, p. 73-74):

O trabalho requer a capacidade de realizar coisas úteis, de estabelecer e manter engajamentos, de prever com outros e para outros algo que não tem diretamente vínculo consigo. É porque, a nosso ver, ele oferece fora de si uma eventual auto-realização graças, precisamente, a seu caráter estruturalmente impessoal, não imediatamente "interessado". O trabalho propõe a ruptura entre as pré-ocupações pessoais do sujeito e as "ocupações" sociais de que este deve desincumbir-se. Por si mesmas, elas lhe permitem inscrever-se numa troca em que os lugares e as funções são nomeados e definidos independentemente dos indivíduos que os ocupam num momento determinado.

Clot (2010) utiliza a clínica da atividade em uma busca pela análise do trabalho e seu desenvolvimento, em prol de reacender o poder de agir dos trabalhadores, seja individualmente ou coletivamente, sendo o trabalho uma tarefa complexa e que está imersa em vários contextos e formas de viver, histórica, ambiental e processual. A clínica da atividade para Vieira e Faita (2003) representa uma abordagem da análise do trabalho centrada numa perspectiva dialógica e do desenvolvimento, a fim de intervir na situação favorecendo transformações na atividade e reestabelecendo o poder de agir dos coletivos de trabalho.

Nessa perspectiva, Bendassolli (2011, p. 87) aponta que o poder de agir diz respeito à ampliação da capacidade de "superação das tensões, ambiguidades, impedimentos e provas das situações reais de trabalho". Isso nos leva a crer que o objetivo da clínica da atividade não é apenas o de criar "espaços de escuta" nos contextos de trabalho, mas sim o de intervir no concreto da atividade, a fim de potencializar as ações a serem desenvolvidas pelo sujeito. Para o autor, o sofrimento no trabalho pode ser compreendido a partir das várias dimensões sobre as quais as atividades acontecem, tal sofrimento não resulta apenas da atividade realizada, mas também da atividade que não pôde ser feita, afetando dimensões,

(i) do corpo (lesões, fadiga, carga excessiva de trabalho, riscos ou ameaças à saúde, etc.); (ii) do psiquismo ou da subjetividade (stress, burnout, transtornos mentais, enfraquecimento ou aniquilação do poder de agir do sujeito etc.); (iii) do relacionamento entre os sujeitos

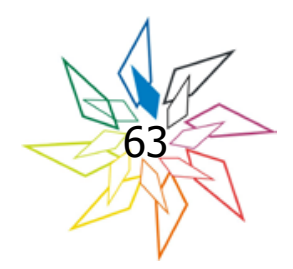


(falta de reconhecimento, enfraquecimento dos coletivos de trabalho, empobrecimento das relações afetivas, competição exacerbada, etc.); (iv) da perspectiva do sujeito moral (assédio, dominação de classes, exclusão social, invisibilidade social, etc.); e (v) do ponto de vista do próprio trabalho (atividade impedida, esvaziada ou suspensa; perda do significado ou da função psicológica do trabalho; ausência de atividade) (BENDASSOLLI, 2011, p. 75).

Para a ampliação dessa ação, em meio ao âmbito coletivo de trabalho, Clot (2010) aponta enquanto estratégia para o enfrentamento das condições de produção de sofrimento que adoece no trabalho a possibilidade de poder agir frente às dificuldades do dia a dia. Com isso, Souza et al (2014, p. 147) em sua pesquisa acerca do poder agir em meio a atividade docente nos mostra que,

A atividade de trabalho é a fonte de criação de novos modos de vivertrabalhar, pois a atenção se volta, sobretudo, para as possibilidades a serem construídas pelos próprios trabalhadores para superarem as situações adversas que surgem no cotidiano escolar.

Mesmo que o trabalho tenha inúmeras formas, percebemos que a organização do trabalho e desenvolvimento da atividade devem ser analisados "junto àqueles que trabalham, no intuito de identificar situações que contribuem para o desenvolvimento e aquelas que são potencialmente perigosas à saúde mental" (VIEIRA, BARROS e LIMA, 2007, p. 159). Na perspectiva do poder de agir, Clot (2010, p. 94) parte da premissa de que todo indivíduo é capaz de lidar com qualquer situação no trabalho, desde que tenha a oportunidade de confrontar-se consigo mesmo, além de receber o apoio dos coletivos de trabalho.

Atualmente, o ambiente de trabalho docente vem sofrendo inúmeras modificações no que diz respeito a aspectos estruturais e pedagógicos para recebimento da demanda com o público que chega com mais frequências as escolas. Nesse sentido, percebemos inúmeros problemas que a escola precisa enfrentar, mesmo sem políticas públicas e suporte dos órgãos responsáveis que favoreçam e garantam condições adequadas para efetivação do seu trabalho. Para isso, Mendes (2006, p. 01) aponta que essa falta de condições que vem provocando doenças nos professores, o que compromete todo o processo de ensino e aprendizagem, fatores que nos levam a lembrar das,

(...) longas jornadas de trabalho que podem chegar a ocupar os três turnos; as pequenas pausas reservadas ao descanso; as refeições rápidas 
e geralmente em lugares sem conforto; o ritmo intenso de trabalho e as exigências de um alto nível de atenção e concentração para dar conta das tarefas. Não se pode deixar também de considerar as condições das salas de aula da maior parte das escolas públicas; sem aclimatização, com iluminação inadequada, desconfortáveis e com excessivo número de alunos (MENDES, 2006, p. 01).

Além disso, surge também a ideia de precarização do trabalho docente, como cita Macedo e Lima (2017, p. 227) que pode ser compreendida a partir das mudanças oriundas da "Nova Gestão Pública" e da intensificação das atividades que afetaram as condições do trabalho docente, com diversas repercussões sobre esses trabalhadores. Dessa forma, a precarização reforça a ideia de que em educação existe uma constante necessidade de competitividade e produtividade, que em alguns momentos pode ser "traduzida como perda de autonomia, desqualificação e até desprofissionalização".

Assim, o trabalho do professor está relacionado com sua saúde, afinal, em muitos casos, "a satisfação no trabalho apresenta influência no desenvolvimento do mesmo" (BAIÃO e CUNHA, 2013, p. 7). O desgaste físico ou mental representa um fator que compromete o desenvolvimento das atividades dos professores frente ao processo escolar de seus alunos, entende-se que "a insatisfação contribui para o estresse ocupacional e para um efeito negativo à saúde" (BAIÃO e CUNHA, 2013, p. 8), prejudicando todos os envolvidos no ambiente de contato docente. Sendo assim, percebemos que,

Boas condições de trabalho englobam não apenas ambientes ergonomicamente adequados, bons salários e administrações éticas, mas também espaços democráticos de discussões acerca da atividade docente, não apenas em locais institucionalmente designados a esse objetivo, mas também em espaços de fala-escuta que sejam construídos no cotidiano e se mostrem atuantes na abertura a novas possibilidades de ensino-aprendizagem, na gestão efetivamente democrática (SOUZA ET AL, 2014, p. 169).

Do ponto de vista da saúde mental e trabalho, Lima (2013, p. 92) aponta a crescente demanda, por parte dos trabalhadores e campos de trabalho, através do estabelecimento de conexão entre esses dois âmbitos, a fim de compreender as relações entre saúde e trabalho, levando em conta que ainda "permanece em aberto a questão do atendimento adequado a ser oferecido a esses trabalhadores", caraterizado pelo sujeito como único responsável.

P/Ula ais Salvador, v. 3, n.3, p. 58-78, set./dez. 2018 
As relações entre trabalho e saúde têm um lugar fundamental nas investigações de Clot (2010), o qual afirma que o ambiente laboral tem conexão direta ou indireta com o surgimento de inúmeras doenças, caracterizando o trabalho como algo que se torna vital para a saúde. Assim, aborda-se que é preciso "criar um contexto para viver: é nesta condição que atividade e saúde são sinônimos" (CLOT, 2010, p. 72). Para isso, a atividade é vista como uma produção ou recriação de um meio de vida que se entrelaça também com a subjetividade, na qual o trabalhador não é apenas um executor de tarefas, mas sujeito ativo do meio em que está imerso.

Nesse contexto, percebemos que o que Clot $(2007 ; 2010)$ traz em se tratando da função psicológica do trabalho e o poder de agir no campo de trabalho, é que saúde se degrada a partir do ambiente de trabalho sempre que um coletivo se torna um conjunto de indivíduos expostos ao isolamento. Isso acontece quando deixa de haver a ação para desenvolver suas atividades partindo do real, o que leva a ideia de que cada um, individualmente, se encontra confrontado diariamente a partir das necessidade e acontecimentos advindos de uma organização do trabalho que, em alguns momentos, deixa seus trabalhadores 'sem voz' face ao real, ao que acontece nas suas atividades.

\section{Procedimentos Metodológicos}

Para respondermos às questões levantadas ao longo desta pesquisa, utilizamos a abordagem metodológica quantitativa e qualitativa, caracterizada enquanto pesquisa mista. A opção foi viabilizada para possibilitar aos professores, participantes da pesquisa, expressassem seus sentimentos e situações vivenciadas na pesquisa, analisando os múltiplos aspectos e particularidades envolvidos nos processos de saúde mental no exercício do trabalho docente com alunos incluídos, além de identificar os fatores condicionantes dos problemas de saúde desses professores.

Nesse contexto, Severino (2007) aponta a preferência pelo uso das designações de abordagem quantitativa e/ou qualitativa, por se tratar de um conjunto que abrange metodologias, envolvendo, eventualmente, diversas referências epistemológicas, o qual afirma que,

São várias metodologias de pesquisa que podem adotar uma abordagem qualitativa, modo de dizer que faz referência mais a seus fundamentos epistemológicos do que propriamente a especificidades metodológicas (SEVERINO, 2007, p. 37).

Optamos também pela pesquisa descritiva, buscando familiarizarmos com o assunto abordado, levando em conta o que aponta Gil (2008) sobre as pesquisas descritivas que possuem como objetivo a descrição das características de uma população, fenômeno ou de uma experiência. Como afirma Severino (2007), isso se faz através de um mapeamento do campo a ser pesquisado, a fim de perceber 
como são as atividades diárias e se afetam a saúde desses profissionais que pertencem a um grupo de professores participantes e de escolas da rede municipal de ensino.

Participaram da pesquisa 21 professores de 3 escolas, no período de fevereiro a junho de 2017, quando foi realizado um mapeamento acerca do campo de atuação e saúde desses profissionais, por meio de um questionário.

A análise dos dados foi realizada através de um levantamento prévio de dados referentes à inclusão de alunos com deficiência na rede municipal de Garanhuns-PE, com acesso fornecido pelos responsáveis legais pelos dados. Utilizamos a Estatística Descritiva, considerado como procedimento inicial na análise de dados, a fim de descrever e resumir o que foi produzido, objetivando organizar os dados de determinada população pesquisada. Os dados qualitativos do questionário foram organizados em duas categorias de análise, construídas a partir dos objetivos do trabalho: O campo de trabalho dos professores e a saúde desses profissionais. Realizamos uma análise dos significados quanto ao campo de atuação dos participantes e como se sentem em meio a prática com os alunos com deficiência, através do que foi relatado no questionário por cada professor participante.

\section{Análise dos Resultados}

O município de Garanhuns, no qual a pesquisa foi realizada, tem aproximadamente 129.408 pessoas, segundo o último Censo (2016), tendo uma taxa de escolarização de 6 a 14 anos de idade de 96,8 \%. No Índice de Desenvolvimento da Educação Básica (IDEB), os alunos dos anos iniciais da rede municipal da cidade tiveram nota média de 4.5, no ano de 2015. Em comparação com cidades do estado de Pernambuco, a nota dos alunos dos anos iniciais colocou a cidade na posição 95 de 185 (IBGE, 2016; IDEB, 2016). Conforme dados fornecidos pela Secretaria Municipal de EducaçãoSeduc e estatísticas do Ministério da Educação- Mec (INEP, 2016), através de um levantamento referente ao ano de 2016, a Rede Municipal de Ensino está organizada em 57 escolas que compõem a rede, com um total de 8.651 alunos matriculados, desse quadro de alunos 337 tem deficiência. Em se tratando de Salas de Recursos Multifuncionais ${ }^{2}$ o munícipio conta com 09 implementadas na rede.

Em 2017, esse quantitativo total de alunos com deficiência incluídos era de 365, segundo dados da Seduc, o que representa um aumento de $7 \%$ desse público nas escolas da rede municipal de ensino

\footnotetext{
${ }^{2}$ Sala de Recursos Multifuncionais são implementadas em escolas públicas de educação básica pelo Ministério da Educação, através de equipamentos, mobiliários, materiais pedagógicos e de acessibilidade destinados a atender as especificidades educacionais de estudantes com deficiência. São essas salas que apoiam o desenvolvimento do Atendimento Educacional Especializado de forma complementar ou suplementar à escolarização desses estudantes (BRASIL, 2013).
} 
em um ano. No qual a rede municipal, em se tratando dos alunos matriculados nos anos iniciais do ensino fundamental era de 8.864 alunos (INEP, 2018). Tomando por base o total de alunos da rede municipal de 2017, citado anteriormente, o quantitativo de alunos com deficiência corresponde a aproximadamente $4 \%$ desse grupo. Das escolas e professores participantes, chegamos a um quadro de 70 alunos com laudos médicos e deficiências diagnosticadas, número que corresponde a $20 \%$ dos 365 alunos com deficiência matriculados na rede. As escolas participantes da pesquisa foram indicadas pela Secretaria Municipal de Educação, que apresentou as instituições que atendem ao público dos anos iniciais do Ensino Fundamental, que funcionavam nos turnos manhã e tarde, do $1^{\circ}$ ao $5^{\circ}$ ano do Ensino Fundamental, com mais alunos com deficiência matriculados.

A fim de traçar o perfil do professor que trabalha com inclusão em Garanhuns e fazem parte de um grupo de professores da rede municipal de ensino, realizamos uma descrição de quem são esses professores, participantes da pesquisa. Do quadro de 21 participantes, $89 \%$ é do sexo feminino, com faixa etária entre 28 e 47 anos, com preponderância de 30 anos, segundo a média realizada, sendo a formação inicial de todos em alguma licenciatura, que vai de Pedagogia a Química, além de terem cursos de especialização nas suas respectivas áreas de formação inicial, sendo a maior parte da amostra composta por pedagogos (54\%), com especialização em Psicopedagogia (33\%).

O tempo de trabalho como professor desse grupo varia de 4 anos até 30 anos de sala de aula, com relação ao processo de inclusão esses professores afirmam que o primeiro contato com esse público aconteceu há meses, do início do ano letivo de 2017, o que para outros tratase de algo presente a mais de 10 anos nas escolas com os quais estiveram em contato. Todos os participantes são professores efetivos da rede que lecionam em turmas dos anos iniciais, de $1^{\circ}$ ao $5^{\circ}$ ano do ensino fundamental, com alunos com deficiência incluídos em suas turmas regulares.

Dos participantes da pesquisa, $58 \%$ desse grupo atua como professor em outra instituição, sendo que os outros $42 \%$ afirmam não conseguir conciliar mais de uma função. Nesse sentido, percebemos que alguns trabalham na mesma escola os dois horários (11\%), outros atuam como pedagogo em instituições de atendimento socioeducativo (5\%), analista no Estado (5\%) e lecionam disciplinas específicas de sua formação (5\%).

Em se tratando de anseios, ao serem questionados como os participantes da pesquisa se sentem trabalhando como professor, as respostas partem do contato com o campo e as necessidades vigentes do dia a dia da profissão. Ao mesmo tempo em que se sentem bem, satisfeitos e realizados, afirmando a importância da profissão como algo gratificante que faz com que sintam que estão contribuindo para a vida dos alunos; mostram a frustração acerca das dificuldades e desvalorização, advindos dos inúmeros desafios do âmbito educacional, o que gera 
uma "sensação de trabalho incompleto, não realizado de maneira efetiva" ( $\left.{ }^{3} \mathrm{P} 6\right)$. Desta forma, Macedo e Lima (2017, p. 229) apontam que muitas ações e iniciativas presentes no cotidiano escolar "precarizam o trabalho docente, corroem sua autonomia e acarretam um contínuo processo de desprofissionalização e desvalorização docente".

Isso leva a um sentimento de angústia e cansaço, como afirma o P14 "hoje em dia não sinto mais prazer, já senti prazer em fazer as atividades", como completa o P18, que "sentia um grande prazer, mas, não consigo mais vivenciar meu dia a dia escolar com tanta alegria, por se tratar de uma atividade que a cada dia faz com que o profissional se sinta "desvalorizado, desprestigiado, acumulando responsabilidades que não são só suas" (P21).

Assim, os fatores considerados estressores advêm da realidade ampla do ambiente escolar com o qual os professores se deparam em meio as suas atividades diárias, sendo apontadas como:

Gráfico 1. Fatores considerados estressores no trabalho docente

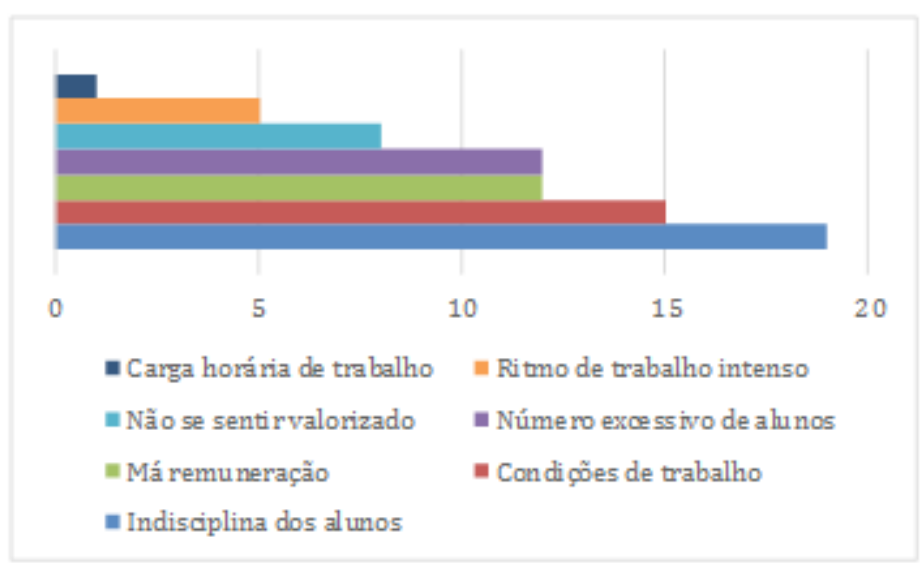

Fonte: Elaborado pelas Autoras. (2017).

Nos seus estudos, Baião e Cunha (2013) apontam como determinantes sociais de saúde no âmbito educacional a superlotação das salas, inadequação estrutural, baixa remuneração,

\footnotetext{
${ }^{3}$ Para assegurar anonimato do professor, a identificação das falas será realizada por letra e número: letra "P" para referir professor, e numeral para referir o número do questionário a tabulação dos dados.
} 
sobrecarga de trabalho, inadequadas condições de trabalho, dupla carga horária, além das atribuições burocráticas do sistema de ensino.

Em se tratando do processo de inclusão, as dificuldades encontradas pelos professores caracterizam-se pela demora na chegada dos apoios de sala para os alunos público da educação inclusiva, além da falta de apoio ${ }^{4}$ pedagógico, seja apoio de sala ou da secretaria, algo mais específico, ajuda, esclarecimentos, como reforça o P12. O espaço físico é inadequado, questões estruturais de um modo geral, a falta de Salas de Recursos Multifuncionais para o AEE. A não parceria da família também dificulta, pois, a mesma não participa e colabora (P19), bem como não aceita as limitações de suas crianças, buscando compreender e colaborar com o processo de ensino e aprendizagem (P21).

Além disso, há também o medo pelo novo, deixando professores receosos e apreensivos com relação ao que vai acontecer, como aponta P13: "Foi bem difícil, o medo do início do ano é o aluno que vai chegar, o medo de como tratar e o que fazer. Percebi que as crianças da turma aceitam mais que os adultos".

Além da falta de apoio do próprio sistema educacional, segundo a P14, "não vejo inclusão, é mais uma ilusão, quando cheguei na escola fiquei angustiada, os alunos gritando na sala, eu não tinha apoio e quando chegou foi mais um cuidador". Nesse sentido, apontamos o que afirma o P18 o que acontece é que o professor "recebe crianças com um grau muito elevado de deficiência que ultrapassa o âmbito pedagógico porque a lei manda".

Percebemos também a ausência de materiais para trabalhar, além de não haver um momento para dedicar tempo exclusivamente para os alunos com deficiência. Isso é o que dificulta a adaptação de atividades com base nos conteúdos propostos em sala, "de acordo com a necessidade de cada estudante portador da necessidade" (P5).

\footnotetext{
${ }^{4} \mathrm{Na}$ Lei $\mathrm{n}^{\mathrm{o}}$ 13.146, de 6 de julho de 2015, que entrou em vigor no início do ano de 2016, institui a Lei Brasileira de Inclusão da Pessoa com Deficiência (Estatuto da Pessoa com Deficiência), que em seu Art. $3^{\circ}$, inciso XIII trata do (...) profissional de apoio escolar: pessoa que exerce atividades de alimentação, higiene e locomoção do estudante com deficiência e atua em todas as atividades escolares nas quais se fizer necessária, em todos os níveis e modalidades de ensino, em instituições públicas e privadas, excluídas as técnicas ou os procedimentos identificados com profissões legalmente estabelecidas (BRASIL, 2015, p. 02).
} 
Em se tratando da formação foi apontada uma necessidade de se ofertar algo para toda a comunidade escolar, que ocorresse com mais frequência e explorasse temas do cotidiano e realidade das escolas. Os profissionais da equipe multidisciplinar seriam para auxiliar o trabalho dos professores e das famílias, a fim de compreender seus alunos e saber como lidar e intervir nas atividades de sala.

Com relação à família, afirma-se a necessidade da presença, suporte e compreensão para que assim, possa haver um diálogo e trabalho em conjunto. Com a falta de recursos e materiais fica quase impossível planejar atividades diferenciadas que possam favorecer o desenvolvimento desses alunos com deficiência. Uma das queixas dos professores é a demora em chegar os apoios para os alunos com deficiência, sendo que quando chegam são estagiários, sem serem especializados ou conhecerem a área da educação inclusiva, além das formações, em sua maioria, não atender a esses profissionais.

Outro questionamento advém da quantidade de alunos com deficiência por sala, considerado excessivo, como mostra a realidade da P6 que tem nove alunos incluídos em sua sala, sendo que a mesma afirma a dificuldade em trabalhar com tamanha diversidade em sua turma, tendo em vista uma turma de $3^{\circ}$ ano que tem também alguns alunos repetentes. A falta de estrutura física é outro fator que dificulta a inclusão, em ambientes favoráveis que possibilitem além da locomoção atividades diversas, com uma equipe multidisciplinar. Além disso, existe a falta de tempo para planejar e estudar, afinal os professores acabam sem tempo para planejamento extra, pois levam muito trabalho para casa e ainda tem questões familiares, esportivas, religiosas e de lazer que precisam exercer para não pensar tanto no trabalho.

Para Bendassolli (2011, p. 87) é importante entender que todo o ambiente educacional precisa ser visto através das possibilidades de ampliação da capacidade de "superação das tensões, ambiguidades, impedimentos e provas das situações reais de trabalho", buscando potencializar as ações a serem desenvolvidas pelo sujeito. Esse autor, infere que todo esse sofrimento no trabalho passa a ser compreendido a partir das várias dimensões sobre as quais as atividades acontecem, sendo que tal sofrimento não resulta apenas da atividade realizada, mas também da atividade que não pôde ser realizada, afetando dimensões individuais e coletivas de trabalho, no quesito autoestima, desenvolvimento de suas atividades com prazer e satisfação.

Para se entender melhor os aspectos ligados à saúde dos professores, como está a saúde desses profissionais, o que eles vêm sentindo e o que estão fazendo para enfrentar tais desconfortos, realizamos um mapeamento acerca do que os professores sentem ao desenvolverem suas atividades cotidianas. Inicialmente, partimos da presença de desconfortos e mal-estar 
no exercício da profissão. Em meio a $69 \%$ de profissionais que sentem algum desconforto no exercício da profissão encontramos seis casos de professores que usam ou já usaram medicação para ansiedade e princípio de depressão. P12 afirma que sente crises de ansiedade, sufocamento, dores de cabeça, rouquidão, insônia, "às vezes preciso sair da sala para respirar, vontade de sair correndo, tenho uma irritabilidade muito grande com o barulho". Para ela, a rotina familiar também pesa muito, devido à velha hierarquia familiar, tudo na casa fica sob sua responsabilidade, marido e filho não ajudam muito. Há também três casos de dificuldades na voz, professores que precisavam estar sempre com uma garrafa de água e já usaram até caixinha de som para ajudar, como é o caso da P13. A P16 afirma sofrer com muita falta de ar e dor de ouvido. Brito, Prado e Nunes (2017, p. 171) consideram que,

Os distúrbios vocais são um dos problemas mais comuns que afetam a saúde dos docentes e acontecem em decorrência do uso excessivo da voz na sala de aula, principalmente, nas turmas superlotadas. Para desempenhar suas atividades, os professores, na maioria das vezes, são obrigados a aumentar o tom de sua voz para sobrepor aos ruídos da sala de aula e de outros ambientes externos, consequentemente, isso pode provocar distúrbios vocais e outros transtornos.

Determinados professores vêm sentindo algum desconforto desde que começou a lecionar. Esse foi o caso de P14 que "há mais ou menos dois anos na escola particular, eu já tinha me afastado, já estava esgotada, me afastei por conta própria", com mais frequência de 7 anos aos dias atuais. Ao sentir algum problema de saúde os participantes da pesquisa afirmam procurar ajuda médica, estão tomando medicação e isso "tranquiliza e o acompanhamento terapêutico controla minhas angústias (P14)". Em alguns casos "quando dá tempo, quando tenho tempo (P8)", "acúmulo por vergonha de procurar um profissional (P12)" ou,

Adio sempre consultas minhas. Vou "empurrando com a barriga" esperando passar, que nunca passa. Quando não dá mais eu vou ao médico. Tomo remédio por conta própria, aqueles que são permitidos (P21).

Nesse sentido, retomamos a ideia apresentada por Clot (2010), ao tratar que a clínica da atividade assegura uma regulação coletiva da ação individual de que o grupo profissional se torna sujeito, sendo que o desenvolvimento do trabalho implica sempre uma dimensão individual e coletiva, e é nesta que se inscreve o poder de agir. Para tanto, as contribuições da clínica da 
atividade fornecem instrumentos que permitem a compreensão das situações de trabalho, de modo que o sujeito possa desenvolver o poder de agir sobre o mundo e sobre si mesmo, de maneira coletiva e individual.

Vale ressaltar que alguns procuram fazer meditação, espairecer com alguma atividade que gosta de realizar: viajar, ler, passear, fazer prevenção para não chegar aos problemas de saúde. Portanto, um importante ponto da pesquisa advém das propostas de intervenção e enfrentamento através da clínica da atividade, frente às diversas formas de mal-estar encontrados no campo de atuação, podendo ter referência com o crescente nível de exigências e as demandas colocadas pelas instituições de trabalho aos indivíduos. Este fator está relacionado a redução das soluções pessoais e coletivas para o enfrentamento de situações a quais foram expostos, "que enfraquecem seu poder de agir, sua capacidade de enfrentamento e de significação de sua própria experiência", como afirma Bendassolli e Soboll (2011, p. 65).

Nesse sentido, na clínica da atividade proposta por Clot $(2007 ; 2010)$ percebemos o enfoque dado a relevância de se investir em espaços coletivos de diálogos no ambiente de trabalho, para que assim os trabalhadores tenham possibilidades concretas de construir outros caminhos, a fim de ampliar o poder de agir dos coletivos de trabalho, uma estratégia para o enfrentamento das condições de produção de sofrimento que adoece no trabalho.

Assim, se destrói os valores de uma cultura de trabalho em grupo e do sentimento de classe ao mesmo tempo em que desmobiliza os coletivos necessários ao enfrentamento dos problemas e a criação das formas para sua superação (MACEDO; LIMA, 2017, p.228).

Deparamo-nos, então, com a necessidade da construção de ambientes que possam trabalhar a individualidade dos seus trabalhadores, a fim de produzir valores a serem utilizados em coletivos operacionais, advindos dos espaços de trabalho. Portanto, a fim de reconhecer que estratégias costumam ser utilizadas para enfrentar algum mal-estar ou desconforto quanto às atividades desenvolvidas no trabalho pelos professores, percebemos que a maioria tenta pensar e fazer outras coisas que não sejam ligadas ao ambiente de trabalho, atividades de lazer, relaxar, manter a calma, tomar medicações para relaxar, meditação, estudar novas estratégias e viver um dia de cada vez.

Nesse sentido, podemos partir desse ponto como sendo fundamental a esta pesquisa, assegurando que o que vem causando frustação, angustia e adoecimento do âmbito docente não advém do trabalho no processo de inclusão escolar. Assim, vale ressaltar que,

P/Ullais Salvador, v. 3, n.3, p. 58-78, set./dez. 2018 
O trabalho docente tem se voltado para a formação inicial e continuada de seus profissionais. Essa temática, sem dúvida, não pode deixar de ser uma das prioridades das pesquisas educacionais, mas ressaltamos que os conhecimentos acadêmicos, foco prioritário dos cursos de formação, não representam a totalidade dos saberes e estratégias de atuação da profissão docente. Existem outros pontos que merecem igual destaque, como o poder do professor de agir sobre seu próprio trabalho e as condições de trabalho encontradas para o exercício de sua profissão (PIZZI; ARAÚJO, 2011, p. 19).

\section{Considerações Finais}

Ao formular as considerações finais dessa pesquisa, nos remetemos ao ponto inicial traçado para que a mesma fosse realizada, partindo da análise da saúde mental do professor dos anos iniciais que atua com inclusão de alunos com deficiência nas escolas regulares da rede municipal de ensino da cidade de Garanhuns-PE, a fim de perceber como a Saúde mental tem se manifestado nesses profissionais, desde sua perspectiva.

Ao utilizarmos a clínica da atividade de Clot (2007; 2010), podemos apontar que essa pesquisa foi fundamentada a partir do princípio de identificação de uma situação partindo do real, advinda do desenvolvimento de suas atividades diárias, levando em conta que o ambiente de trabalho é composto de influências individuais e coletivas daquele contexto. Para o autor, a clínica da atividade busca analisar o trabalho e o desenvolvimento das suas atividades cotidianas, exploradas através da atividade laboral, tendo como objetivo ativar o poder de agir dos trabalhadores seja individualmente ou coletivamente, em meio as suas tarefas, levando em conta a dimensão do trabalho e o contexto no qual está inserido.

Constatamos um estranhamento dos professores participantes no fato da pesquisa ter sido algo especificamente com eles, sem ir para sala de aula observar os alunos ou a sua prática em sala, pois a maioria das pesquisas e pesquisadores que chegam à escola vem em busca disto, segundo o relato dos participantes. Vale ressaltar também a empolgação que alguns participantes demonstraram, além do desejo em participar da pesquisa que, segundo eles, traria outro olhar acerca da inclusão dos alunos com deficiências nas turmas regulares e 
de como eles estão em meio a esse ambiente de trabalho, sendo essa uma maneira de enxergálos como sujeitos participantes desse processo de inclusão educacional.

Para tanto, percebemos que alguns professores participantes desde o início da produção dos dados demonstravam insegurança e receio em expor situações de sofrimento que estavam afetando todos os setores com os quais se tinha contato. O que nos leva a crer que o trabalho envolvendo a saúde mental e o trabalho docente é algo que precisa ainda ser explorado e levado ao âmbito educacional, a fim de auxiliar esses profissionais no desenvolvimento de suas atividades.

O problema de pesquisa e objetivos foram respondidos, apontando que o processo de inclusão não se trata do fator chave que desencadeia o adoecimento desses profissionais, tendo em vista a influência de um ambiente repleto de fatores que geram desconforto nos professores, relacionados as condições de trabalho, questões financeiras, burocráticas, pedagógicas, entre outras.

\section{REFERÊNCIAS}

ANTUNES, Ricardo. Os sentidos do trabalho: ensaio sobre a afirmação e a negação do trabalho. $6^{\text {a }}$ ed. São Paulo: Boitempo Editorial, 2002.

ARAÚJO, Lilian Maria Badaró Ferreira; SOUSA, Rosânia Rodrigues de. O adoecimento psíquico de professores da rede pública estadual: perspectiva dos docentes. XXXVII Encontro da ANPAD, Rio de janeiro, set. 2013.

BAIÃO, Lidiane de Paiva Mariano; CUNHA, Rodrigo Gontijo. Doenças e/ou disfunções ocupacionais no meio docente: uma revisão de literatura. Revista Formação@docente, Belo Horizonte, vol. 5, n¹, p. 06-21, jan. jun. 2013.

BENDASSOLLI, Pedro Fernando. Mal-estar no trabalho: do sofrimento ao poder de agir. Revista Mal-estar e subjetividade, Fortaleza, vol. 10, $\mathrm{N}^{\mathrm{o}} 1$ - p.63 - 98 - Mar./2011.

BENDASSOLLI, Pedro Fernando; SOBOLL, Lis Andrea Pereira. Clínicas de trabalho: filiações, premissas e desafios. Caderno de psicologia social do trabalho, vol. 14, n. 1, pp. 5972, 2011. Disponível em: <http://www.revistas.usp.br/cpst/article/view/25716/27449> Acesso em: abril/ 2017. 
BRASIL. Ministério da Educação. Programa Implantação de Salas de Recursos Multifuncionais. 2013. Disponível em: <http://portal.mec.gov.br/pnpd/194-secretarias-112877938/ secad-educacao-continuada-223369541/17430-programa-implantacao-de-salas-de-recursos-multifuncionais-novo>. Acesso em 08 jun. 2016.

Lei no 13.146, de 6 de julho de 2015. Lei Brasileira de Inclusão da Pessoa com Deficiência (Estatuto da Pessoa com Deficiência). Presidência da República. Casa Civil. Brasília, DF, 2015.

BRITO, Regivane dos Santos; PRADO, Jany Rodrigues. NUNES, Claudio Pinto. As condições de trabalho docente e o pós-estado de bem-estar social. Revista Tempos e Espaços em Educação, São Cristóvão, Sergipe, Brasil, v. 10, n. 23, p. 165-174, set./dez. 2017. Dísponivel em: <http://dx.doi.org/10.20952/revtee.v10i23.6676> Acesso em: março/ 2016.

CARLOTTO, Mary Sandra. A síndrome de burnout e o trabalho docente. Psicologia em Estudo, Maringá, v. 7, n. 1, p. 21-29, jan. jun. 2002.

CLOT, Yves. A função psicológica do trabalho. 2. Ed. Petrópolis-RJ: Vozes, 2007.

. Trabalho e poder agir. Belo Horizonte: Fabrefactum, 2010.

CODO, Wanderley (coord.). Educação: carinho e trabalho- burnout, a síndrome de desistência do educador, que pode levar à falência da educação. Petrópolis: Vozes, 1999.

ESTEVE, José. Manuel. O mal-estar docente: a sala de aula e a saúde dos professores. Trad. de Durley de Carvalho Cavicchia. Bauru, São Paulo: EDUSC, 1999.

GASPARINI, Sandra Maria; BARRETO, Sandhi Maria; ASSUNÇÃO, Ada Ávila. O professor, as condições de trabalho e os efeitos sobre sua saúde. In: Educação e pesquisa, São Paulo, v. 31, n. 2, p. 189-199, mai. ago, 2005.

GIL, Antonio Carlos. Métodos e técnicas de pesquisa social. 6a. Ed. São Paulo: Atlas, 2008.

INEP. Instituto Nacional de Estudos e Pesquisas Educacionais Anísio Teixeira. Sinopse Estatística da Educação Básica 2016. [online]. Brasília: Inep, 2017. Disponível em: <http: // potal.inep.gov.br/sinopses-estatisticas-da-educacao-basica > . Acesso em: 20 mai. 2018.

Instituto Nacional de Estudos e Pesquisas Educacionais Anísio Teixeira. Sinopse

Estatística da Educação Básica 2017. [online]. Brasília: Inep, 2018. Disponível em: <http: // potal.inep.gov.br/sinopses-estatisticas-da-educacao-basica>. Acesso em: 20 mai. 2018. 
LEVY, Gisele Cristine Tenório de Machado; SOBRINHO, Francisco de Paula Nunes. A síndrome de burnout em professores do ensino regular: pesquisa, reflexões e enfrentamento. Rio de janeiro: Cognitiva, 2010.

LIMA, Maria Elizabeth Antunes. Saúde mental e trabalho: limites, desafios, obstáculos e perspectivas. In: Caderno de Psicologia Social do trabalho, Belo Horizonte- MG, vol. 16, n. especial 1, p. 91-98, 2013.

MACEDO, Jussara Marques. LIMA, Miriam Morelli. Fundamentos teóricos e metodológicos da precarização do trabalho docente. In: Revista Trabalho, Política e Sociedade - RTPS, Vol. II, n ${ }^{\circ}$ 03, p. 219-242, jul-dez/2017.

MENDES, Maria Luiza Maciel. Condições de trabalho e saúde docente. In: VI seminário da redestrado- regulação educacional e trabalho docente- UERJ- Rio de janeiro- 06 e 07 de novembro de 2006.

NÓVOA, Antonio. Formação de professores e profissão docente. In: Os professores e a sua formação. Lisboa, Portugal: Publicações Dom Quixote, 1997.

PIZZI, Laura Cristina Vieira; ARAÚJO, Isabela Rosália Lima. (Re) criações do estilo docente e seu poder de agir: os efeitos da precarização. In: Revista cocar Belém, vol. 5, n. 10, p. 19-28, jul./dez. 2011.

SEVERINO, Antonio Joaquim. Metodologia do trabalho científico. 23. Ed. São Paulo: Cortez, 2007.

SOUZA, Aline Silveira de et al. As comissões e o núcleo de saúde dos trabalhadores: tateando "(re)existências" da atividade docente. In: ROSEMBERG, Dulcinea Sarmento. RONCHI FILHO, Jair. BARROS, Maria Elizabeth (org). Trabalho docente e poder de agir: Clínica da atividade, devires e análises. Vitória: EDUFES, Cap. 5., p. 147- 176., 2014.

SOUZA, Aparecida Neri de; LEITE, Marcia de Paula. Condições de trabalho e suas repercussões na saúde dos professores da educação básica no Brasil. In: Educação e sociedade, Campinas, v. 32, n. 117, p. 1105-1121, out. Dez. 2011.

TITTONE, Jaqueline. Subjetividade e trabalho. Porto Alegre: Ortiz, 1994. 
VIEIRA, Carlos Eduardo Carrusca. BARROS, Vanessa Andrade. LIMA, Francisco De Paula Antunes. Uma abordagem da psicologia do trabalho, na presença do trabalho. In: Psicologia em revista, Belo Horizonte, v. 13, n. 1, p. 155-168, jun. 2007.

VIEIRA, Marcos; FAÏTA, Daniel. Quando os outros olham outros de si mesmo: reflexões metodológicas sobre a autoconfrontação cruzada. In: Polifonia, Cuiabá, EDUFMT, nº 07, pp. 27-65, 2003. 